\title{
Hypercalcemia as a Presenting Clinical Manifestation of Adenocarcinoma of the Colon
}

\author{
Angelo Argento
}

\begin{abstract}
Hypercalcemia is rarely associated with colon cancer. It is related to overexpression of parathyroid hormone-related protein (PTH-rp) in malignant cells of the primary colon tumor and metastases. A 44 year old lady presented for evaluation of severe hypercalcemia $(15.7 \mathrm{mg} / \mathrm{dL})$ associated with abdominal pain, nausea and constipation. She was diagnosed with metastatic colon cancer involving the liver. Therapy for hypercalcemia consisted of intravenous bisphosphonate and saline hydration. Hypercalcemia remained resistant and refractory to treatment despite resection of the colon tumor. She died soon after admission to hospice. It is proposed that malignant cells of the primary colon tumor and distant metastases, in this patient, were the site of ectopic PTH-rp secretion resulting in hypercalcemia. This case illustrates the significance of recognizing hypercalcemia as a potential clue in detecting underlying colon cancer involving overproduction of PTH-rp. It also exemplifies the poor prognosis expected with this type of humoral hypercalcemia of malignancy and the difficulty encountered when trying to achieve normalization of calcium in this setting.
\end{abstract}

Keywords: Hypercalcemia; Colon cancer; PTH-rp; Prognosis

\section{Introduction}

Hypercalcemia is commonly associated with solid tumors seen in lung, breast and kidney cancer in addition to hematologic malignancy such as multiple myeloma, leukemia and lymphoma [1]. In contrast, carcinoma of the colon is rarely associated with hypercalcemia which usually implicates a poor prognosis and survival rate [2]. The cell types most often discovered, during histological examination of colon cancer with hypercalcemia, are adenocarcinoma and

Manuscript accepted for publication May 10, 2012

Internist, Valley View Regional Hospital, 2020 Arlington, Suite 2, Ada, OK 74820, USA. Email: argento99@medscape.com

doi: http://dx.doi.org/10.4021/wjon512w adenosquamous carcinoma [3-7]. Hypercalcemia presenting as a manifestation of solid tumors is typically due to production of a humoral factor or hormone, by malignant cells, and rarely from local osteolytic destruction secondary to bony metastases. Humoral hypercalcemia of malignancy (HHM) is secondary to overproduction of a polypeptide, belonging to the parathyroid hormone (PTH) family, known as parathyroid hormone-related protein (PTH-rp) [8, 9]. This entity, described as paraneoplastic syndrome, is characterized by ectopic hormone production in the setting of underlying malignancy. Clinical awareness of hypercalcemia as a diagnostic clue and accompanying manifestation leading to detection of underlying colon cancer has become increasingly important because of its prognostic implication and refractoriness to limited available treatment options aimed at normalizing calcium.

\section{Case Report}

A 44-year-old African American female with history of peptic ulcer disease, mitral valve prolapse and anemia presented to the clinic for evaluation of epigastric abdominal pain, nausea and constipation. Review of systems was positive for weight loss of approximately 15 to $20 \mathrm{lbs}$ and fatigue; negative for fever, hematochezia or melena. Medication consisted of dicyclomine, metoclopramide, sucralfate and ferrous sulfate recently prescribed by ER physician for abdominal symptoms. Past surgical history significant for total abdominal hysterectomy with bilateral salpingo-oophorectomy. Family history negative for colon cancer and her mother died from lung cancer at age 70. Physical examination revealed an obese female with blood pressue of $163 / 88 \mathrm{mmHg}$ and epigastric tenderness to palpation. There were no palpable masses or lymphadenopathy detected. Stool guaic was negative. Laboratory investigation showed calcium level of 15.7 $\mathrm{mg} / \mathrm{dL}$, phosphorous $2.8 \mathrm{mg} / \mathrm{dL}$, sodium $136 \mathrm{meq} / \mathrm{L}$, potassium $3.5 \mathrm{meq} / \mathrm{L}$, chloride $100 \mathrm{meq} / \mathrm{L}$, bicarbonate $31 \mathrm{meq} / \mathrm{L}$, BUN $30 \mathrm{mg} / \mathrm{dL}$, creatinine $1.9 \mathrm{mg} / \mathrm{dL}$, glucose $121 \mathrm{mg} / \mathrm{dL}$, total protein $8.1 \mathrm{gm} / \mathrm{dL}$, albumin $3.6 \mathrm{gm} / \mathrm{dL}$, total bilirubin $0.4 \mathrm{mg} / \mathrm{dL}$, SGOT $75 \mathrm{U} / \mathrm{L}$, SGPT $50 \mathrm{U} / \mathrm{L}$ and alkaline phosphatase $227 \mathrm{U} / \mathrm{L}$. White blood cell count was $11.3 \mathrm{~K} / \mathrm{mm}^{3}$, 


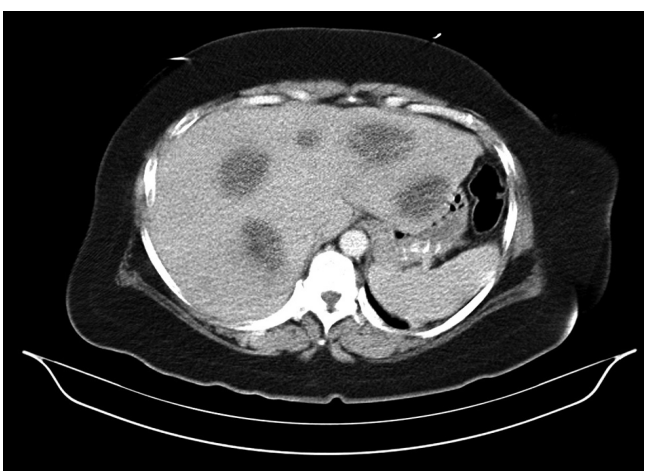

Figure 1. CT scan of the abdomen and pelvis with and without contrast illustrating multiple liver lesions, largest measuring 4 to $5 \mathrm{~cm}$.

$\mathrm{HgB} 8.6 \mathrm{gm} / \mathrm{L}$, HCT $27.2 \%$, MCV $75.6 \mathrm{fL}$ and platelet count $778 \mathrm{~K} / \mathrm{mm}^{3}$, CEA $702 \mathrm{ng} / \mathrm{mL}$. Intact PTH was not measured. Instead, the carboxy (C)-terminal PTH assay (includes Cterminal, intact PTH and midmolecule) was measured and found to be within normal limits at $48 \mathrm{ng} / \mathrm{dL}$ (reference range $<88 \mathrm{ng} / \mathrm{dL}$; Specialty Laboratories, Valencia, CA).

She was admitted for evaluation and treatment of severe hypercalcemia. After administering IV pamidronate (Aredia) along with normal saline and IV furosemide, calcium level gradually declined from 15.7 to $10.1 \mathrm{mg} / \mathrm{dL}$ over a period of 7 days. CXR was normal and screening mammogram revealed BIRAD 2 benign findings. CT scan of abdomen with and without contrast showed multiple lesions within the liver (Fig. 1). Colonoscopy revealed a $3 \mathrm{~cm}$ ulcerated mass near the splenic flexure (biopsy showed moderately differentiated adenocarcinoma). EGD was normal. The following day after surgical consultation she was taken to the operating room for exploratory laparotomy undergoing segmental resection of the transverse colon, where the identified cancer was located (Fig. 2). Open core needle biopsy of a liver mass demonstrated adenocarcinoma compatible with metastasis from colon.

She was admitted on two additional occasions about 1 week apart, 6 days after initial hospital discharge, for refractory hypercalcemia associated with nausea, vomiting, lethargy and confusion. Temporary and partial response was observed to IV pamidronate, in addition to saline diuresis and IV furosemide, lowering calcium from 15.6 to $12.8 \mathrm{mg} / \mathrm{dL}$ over period of 10 days. On the second occasion, hypercalcemia was partially corrected with IV zoledronic acid (Zometa), along with saline diuresis and furosemide, dropping calcium from 16.2 to $13.1 \mathrm{mg} / \mathrm{dL}$ over 3 days. After being admitted to hospice, her condition continued to deteriorate and she died 7 weeks after initial hospital admission.

\section{Discussion}

Hypercalcemia, commonly found in malignancy, is a very

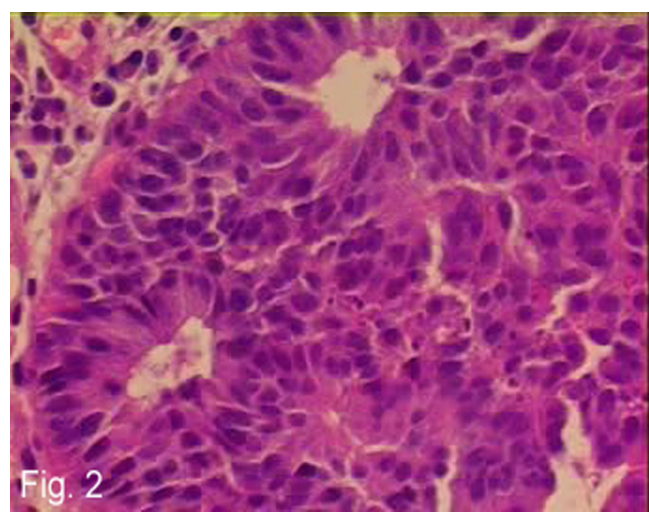

Figure 2. $\mathrm{H}$ and $\mathrm{E}$ stain of primary colon tumor showing poorly differentiated adenocarcinoma of the colon.

rare clinical manifestation of colon cancer, most frequently in association with poorly differentiated adenocarcinoma, demonstrated in Figure 2, and adenosquamous carcinoma of the colon [2-7]. Symptoms of hypercalcemia include nausea, vomiting, constipation, abdominal pain, confusion and fatigue most of which were experienced by this patient.

HHM associated with colon cancer has been shown to be mediated by overexpression of PTH-rp in tumor cells [9]. Normal cells also produce PTH-rp which plays a physiological role in skeletal development, epithelial cell growth, smooth muscle relaxation and keratinocyte differentiation [10]. The amino (N)-terminal of PTH-rp shares partial amino acid sequence and tertiary conformational homology with PTH, enabling it to bind to the PTH receptor leading to increased bone resorption and distal tubular calcium reabsorption along with decreased proximal tubular reabsorption of phosphate; ultimately resulting in hypercalcemia and hypophosphatemia [11]. Patients with hypercalcemia and colon cancer have elevated serum PTH-rp levels with low normal to suppressed PTH in most cases; in addition to, positive staining for PTH-rp in neoplastic cells of both the primary colon tumor and liver metastases [3-7]. Serum PTH-rp was not measured and immunohistochemical staining for PTHrp was not performed in this patient. Although intact PTH was not measured in this patient, the C-terminal PTH which includes intact PTH was within normal range, supporting the presence of ectopic PTH-rp as the cause of hypercalcemia in this case.

Colon cancer in the presence of hypercalcemia indicates advanced stage disease with liver being the most common site of distant metastases followed by lung and bone. Skeletal metastasis from colon cancer is very infrequent, occurring in approximately $5-10 \%$ of patients. Retrospective studies have demonstrated a temporal pattern in which liver and, more accurately, lung precedes bone metastasis in all cases of diagnosed colon cancer $[12,13]$. It is unlikely, in this patient, that hypercalcemia was due to local osteolytic tumor invasion in the absence of lung metastases which, is more 
precise than liver metastases at predicting, and in most cases precedes bony metastasis in patients with colon cancer.

Hypercalcemia, when present, in the setting of underlying colon cancer is a poor prognostic indicator with survival time ranging from 6 days to 7 months. Median survival has been shown to be approximately 4 weeks with mean survival of 8 weeks; one reported case of patient still alive with disease at 13 months [3-6]. HHM associated with colon cancer is often refractory and resistant to treatment, usually recurring within 2 - 3 weeks after therapy is discontinued [14]. Available treatment options for correcting hypercalcemia in these patients are limited and include calcitonin, IV bisphosphonates such as pamidronate and zoledronic acid, along with saline hydration and furosemide. Calcitonin is used in combination with saline hydration for the initial management of severe hypercalcemia ( $>14 \mathrm{mg} / \mathrm{dL}$ ) because it lowers serum calcium concentration rapidly by a maximum of 1 to $2 \mathrm{mg} / \mathrm{dL}$ beginning within $4-6$ hours. Bisphosphonates are more potent and preferred agents, in conjunction with calcitonin and saline, for managing malignancy-related hypercalcemia with maximum effect occurring in 2 - 4 days $[15,16]$. Zoledronic acid is more powerful and sometimes favored over pamidronate because it can be administered over a shorter period, 15 minutes compared to 2 hours [17].

Although PTH-rp was not measured and immunohistochemical staining for PTH-rp was not performed in this case, a normal level of C-terminal PTH which includes intact PTH in association with hypercalcemia, suggests the presence of a humoral factor or hormone, namely PTH-rp. It is believed with high likelihood that malignant cells of the primary colon tumor and liver metastases, in this patient, were the focus of ectopic PTH-rp production and secretion leading to humoral hypercalcemia of malignancy. This case emphasizes the importance of recognizing hypercalcemia as a presenting manifestation and potential clinical diagnostic clue in detecting underlying colon carcinoma as part of a paraneoplastic syndrome involving overproduction of PTH-rp.

\section{Disclosures}

Dr. Angelo Argento reports no disclosures.

\section{References}

1. Warrell RP Jr. Metabolic Emergencies. In: DeVita VT Jr, Hellman S, Rosenberg SA, editors. Cancer: Principles and Practice of Oncology, 5th ed. Philadelphia: Lippincott-Raven; 1997:2486-2493.

2. Kubota H, Koyama y, Hojo K, et al. Adenosquamous cell carcinoma of the colon with severe hypercalcemia. Report of two cases. Jpn J Clin Oncol 1980; 10:311-20.
3. Sakata J, Wakai T, Shirai Y, Sakata E, Hasegawa G, Hatakeyama K. Humoral hypercalcemia complicating adenocarcinoma of the sigmoid colon: report of a case. Surg Today. 2005;35(8):692-695.

4. Thompson JT, Paschold EH, Levine EA. Paraneoplastic hypercalcemia in a patient with adenosquamous cancer of the colon. Am Surg. 2001;67(6):585-588.

5. Fujita T, Fukuda K, Nishi H, Takao T, Ohmura Y, Mano M, Komatsubara S. Paraneoplastic hypercalcemia with adenosquamous carcinoma of the colon. Int J Clin Oncol. 2005;10(2):144-147.

6. Lortholary AH, Cadeau SD, Bertrand GM, Guerin-Meyer VI, Gamelin EC, Audran MJ. Humoral hypercalcemia in patients with colorectal carcinoma: report of two cases and review of the literature. Cancer. 1999;86(11):22172221.

7. Links M, Ho H, Clingan P, Diamond T. Hypercalcaemia in a patient with fatal adenosquamous carcinoma of the colon. Med J Aust. 1994;160(5):286-287.

8. Martin TJ, Suva LJ. Parathyroid hormone-related protein in hypercalcemia of malignancy. Clin Endocrinol 1989; 31:631-647.

9. Henry JG, Mitnick M, Dann PR, Stewart AF. Parathyroid hormone-related protein-(1-36) is biologically active when administered subcutaneously to humans. J Clin Endocrinol Metab. 1997;82(3):900-906.

10. Moseley JM, Gillespie MT. Parathyroid hormone-related protein. Crit Rev Clin Lab Sci. 1995;32(3):299-343.

11. Heys SD, Smith IC, Eremin O. Hypercalcaemia in patients with cancer: aetiology and treatment. Eur J Surg Oncol. 1998;24(2):139-142.

12. Roth ES, Fetzer DT, Barron BJ, Joseph UA, Gayed IW, Wan DQ. Does colon cancer ever metastasize to bone first? a temporal analysis of colorectal cancer progression. BMC Cancer. 2009;9:274.

13. Katoh M, Unakami M, Hara M, Fukuchi S. Bone metastasis from colorectal cancer in autopsy cases. J Gastroenterol. 1995;30(5):615-618.

14. Gurney H, Grill V, Martin TJ. Parathyroid hormonerelated protein and response to pamidronate in tumourinduced hypercalcaemia. Lancet. 1993;341(8861):16111613.

15. Bilezikian JP. Clinical review 51: Management of hypercalcemia. J Clin Endocrinol Metab. 1993;77(6):14451449 .

16. Berenson JR. Treatment of hypercalcemia of malignancy with bisphosphonates. Semin Oncol. 2002;29(6 Suppl 21):12-18.

17. Major P, Lortholary A, Hon J, Abdi E, Mills G, Menssen HD, Yunus F, et al. Zoledronic acid is superior to pamidronate in the treatment of hypercalcemia of malignancy: a pooled analysis of two randomized, controlled clinical trials. J Clin Oncol. 2001;19(2):558-567. 